\title{
OTHERNESS REPRESENTED IN TODD DURHAM'S HOTEL TRANSYLVANIA
}

\author{
Nasrum[1], Syahruni Junaid[2], Ashril Awwab[3]
}

\author{
[1]nasrum.marjuni@uin-alauddin.ac.id, [2]syahruni.junaid@gmail.com, [3]ashrilawwab3@gmail.com \\ Alauddin State Islamic University of Makassar \\ Makassar, South Sulawesi, Indonesia
}

\begin{abstract}
This research discusses the otherness concept in Hotel Transylvania film. It is an animation movie that tells about the conflict between human with monster, in which the main character Dracula as a monster had a terrible memory with the human that makes him isolated himself and all monsters from humans' intervention. The research aims to deconstruct how the otherness concept appeared in the film's manuscript. This research uses the content analysis method. In analyzing the data, the researchers use the deconstruction theory from Jacques Derrida to reveal the concept of otherness, which is the primary purpose of this research. Furthermore, this research focuses on the characters who brought the concept of otherness through their dialogue. As a result of this research, the researchers find that both humans and monsters are projecting each other's identity based on their perspective. The implication of this research is to give understanding to readers how the otherness concept is close to our daily life, and even we do not realize it has frequently happened.
\end{abstract}

Keywords: otherness, deconstruction, derrida, humankind.

\section{INTRODUCTION}

The otherness is viewed in many aspects, including in social interaction, like East by West and Women by Men. It has a strong influence on interpersonal interaction. It is dominantly defined as a harmful generalization or discrimination used for one group by another group just because they are different. Otherness, in representing difference, as Hall (1997, p. 258) points out, allows us to view group members as being, all the same, to isolate and clarify a few of the characteristics and to relate them without exceptions to a whole individual. It is creating provocative generalizations, producing incorrect assumptions, and causing unwanted discrimination.

Otherness is highly related to identity, in which we project the identities of the others based on our experience or perception, and based on these, we unconsciously project our own identity (Okolie, 2003, p. 2). Thus, otherness constructs identity addiction; indeed, without the "Other," identity is meaningless. Therefore, it defines a notion of normality based on the existence of an identity, in which a dominant in-group ("us," normal) builds a dominated out-group ("them," Other) by marginalizing a real or assumed difference, and maybe as a cause for possible discrimination (Staszak, 2008, p. 1). However, otherness eventually created characteristics of 'us vs. them' (Helsby, 2005, p. 145); otherness (them) is different and needs to be dominated by the majority or predominant group.

Otherness is challenging to understand without constructing the majority and minority. However, as the representations of the different groups, otherness does not emerge by itself but by the dominant group's intervention. Furthermore, this concept constructs our mind to think if another group that differs from us is wrong; therefore, we could probably underestimate them (Other).

Otherness representations are also constituted in the film industry as a medium of entertainment; for instance, in the last decade of the 20th century, most Disney animation 
films portray otherness representations by using traditional culture, figurative language, and visualizations in narrating the story. In terms of identities, otherness representations in Disney film appear in the opening sequence of Aladdin (1992), where the Arabic culture, which is at the center of narration, is explicitly defined as barbaric from the very first lines making up the opening song.

Otherness is also represented in another film which an animation film: Hotel Transylvania (2012), is a story of a powerful Dracula who builds a hotel only for monsters (ghosts); he thinks that the existence of human is bothering or even breaking the sanctuary of monster's place, the hotel. The Dracula has a daughter, Mavis. He is trying hard to avoid Mavis from the human. He also makes propaganda about humans to all the monsters, including Mavis. Then, one day, a human teenager comes to the hotel. He is a traveler and getting lost to the hotel. The Dracula is frightened not because the man will probably kill their population, but he scared because the other monsters will know if the human is in the hotel, they will leave the hotel, then what he had thought ever since about the sanctuary of the hotel will be believed as a lie. However, Dracula is trying anything to get the human away from the hotel. He even makes over, changes the appearance of the man to be seen likely as monsters in order to not to freaking the other monsters out.

Suddenly, Mavis and the human are falling in love. Dracula is getting mad; he threatened the human to leave Mavis. Unfortunately, the humans compromised revealed. Then, the human is leaving the hotel. Mavis does not care if he is a human; she is as sad as the human left the hotel. As a father, Dracula cannot stand to see his lovely daughter sad. He then chased the human in order to make Mavis happy again. The Dracula and some of the monsters are going to human places. Then, they found that human is not as bad as they think. They even get helped to bring them faster to the man whom they chased. Finally, the monsters are not thinking poorly of humans anymore, and they could accept human existence in their world.

Otherness representations are portrayed in the story, in which Dracula does not want others, specifically humans, to be a part of monsters' civilizations. The researchers analyze the concept of otherness based on Deconstruction theory, in contrary, in fact this film and reviews about this film is nothing about otherness. However, the researchers need to use deconstruction approach to prove and explore the concept within the film. In order to prove and explore the concept within the film, the researchers identify the characters' representations, dialogues, and context using content analysis.

Therefore, the purpose of this research is to find out how otherness is represented in Todd Durham's Hotel Transylvania. The method used is descriptive qualitative to describe the object or subject's facts and characteristics systematically.

\section{OTHERNESS}

As Hall (1997, p. 258) explained, otherness allows one to consider the members of the group as being all the same, isolate and describe some of the characteristics, and apply them to a person without exception. It makes incorrect assumptions, develops negative conclusions, and induces inappropriate discrimination. Otherness constructs the connection of identity; in addition, without the identity of the "other," it is meaningless. It, therefore, defines a notion of normality based on the presence of an identity in which the dominant in-group ("us," normal) constructs a marginalized out-group ("them," Other) by marginalizing an actual or presumed gap, and maybe as a cause of potential discrimination (Staszak, 2008, p. 1).

According to Augé (2014), there are two forms of otherness. The first form is the otherness of internal use (distinctness from "others"), and the second is the otherness of external use, which is more radicalistic (it is about excluding, even eliminating the other). Thus, the concept of otherness is like an indirect and harmful way of thinking of someone as different.

We can see that the ways to relate to otherness are depending on knowing differences from a particular identity. We can define otherness by defining identity. This articulation resulted from the categorization process equivalent to each culture, an opposition between the similar and the different. It produced the relationship between me - the other illustrated by these opposite pairs, as follows: similar-different, local- 
foreign, close-far, friend-enemy, east-west, majority-minority, and many others. When all these aspects of otherness are identified, we can consider the definition of identity. Identity, therefore, is about identifying otherness. During the interactional communication process, identification of individuals as belonging to some social categories. Then, media permanently construct and reconstruct representations that refer to these identities.

The directions of the otherness are shaped by the social forces, as Hazell (2009) suggested, in other words, to win and retain their authenticity in the world. A person will make the image of otherness through the concept of the relationship he has with the "other," which will influence him in understanding and behaving towards the "other."

\section{FILM AS A LITERARY WORK}

The film incorporates the dynamic interplay of light and shadow, manipulates 3D space, and relies on moving images with complex rhythms. Furthermore, film interacts with pictures, metaphors, and signals, with actions and movements, verbal dialog, and explicitly with actual images and sounds. Finally, it extends or compresses space and time, moving freely across its broad borders. Thus, it has a relation to other literary forms according to Boggs and Petría (2008, p. 3).

The film is an artwork, like other literature pieces. It is a dynamic text textual, procedural, and graphical code structured to create a particular meaning (Nikmah, 2014, p. 1). The film is a partial distortion, just as if the theatre in which people live is being identified (Arnheim, 2006, p. 28). Nevertheless, it gives the impression of real-life to a certain degree.

The film is more straightforward and involves less text; it is pretty different from books and poems, that the story depends on the text, which takes more time to interpret, while film needs further research to understand the hidden meaning of fewer texts.

Arnheim (2006, p. 29) points out; likewise in film or theater, the illusion takes place, as long as the essential elements of every event are shown, moreover, as long as the people on the screen are human and live, we do not need to have them in front of us as powerful living beings or view them occupy real space, in other words, they are as natural as they are.
However, on the other hand, in film, objects and events are viewed in a live and imaginary way simultaneously, and simple lighting patterns on the projection screen are actual objects. After all, this is the fact if the film is classified as a literary work.

\section{DECONSTRUCTION}

In this research, the researchers use the Deconstruction theory by Jacques Derrida to identify the concept of otherness within the film's manuscript, based on the characters, which is the primary purpose of this paper. The word deconstruction was first invented in the late 1960 s by the French philosopher Jacques Derrida and influenced America from the 1970s to the 1980s (Enwald, 2004, p. 50). The term 'deconstruction' closely related not to the term 'destruction,' but to the word 'analysis.' Deconstructive reading does not imply the weaknesses or stupidities of the writer, but the need in which what he sees systematically connected to what he does not see (Derrida, 1981, p. xiv).

Deconstruction movements do not destroy the structures from the outside. The movements are not practical and efficient, nor can they have a specific target, even by dealing with those structures. Necessarily working from the inside, borrowing all the components from the old structure, borrowing them structurally, in which, this is what the person who started the same work in another area (Derrida, 1997, p. 24). As Derrida (1981, p. 43) says that the textual field out of the workings of intertextuality or infinite referral from trace to trace, the re-inscription, within the differential field of the spacing of theme effects, substance effects, and content.

Generally, the task of deconstruction reveals the problematic nature of discourse centered on the part of others to deconstruct phenomenology by conceptually modifying the limits. While Habib (2005, p. 649) writes that deconstruction is "a way of reading, a way of writing and, most of all, a way of challenging the interpretation of texts based on traditional views of the consistency of the human self, of the external world, and of language and meaning." It concludes that deconstruction is a way of reading philosophic texts to question these texts directly, forcing the texts to take the role of their contradictions and exposing the 
oppositions the texts have ignored or repressed.

Ghofur (2014, p. 72) considers deconstruction as a new perspective in the literature study. Deconstruction is precisely an opportunity to develop anything that has not received attention. Deconstruction also allows any intellectual exploration to occur without an obligation by a single rule that is considered universally applicable. According to Derrida in Ryan (2019, p. 23), breaking the circle of departure and returning to the complete origin of consciously defined context is one point of deconstruction.

Besides, Derrida also focuses first on binary oppositions within a text, such as a man/woman, major/minor. Every binary opposition is marginal because each selfidentity is defined as a margin between the two binary poles. Each case is differential, both poles of a binary at once and neither one exclusively. In the binary opposition of theory and practice, the margin limits where theory and practice both meet and divide, where theory establishes what it is, its self-identity, concerning what is other than or different from it (Ryan, 2019, p. 12).

Second, it shows how these opposites are related: central, natural, and privileged, while the other is ignored, repressed, and marginalized. Third, it negates or subverts the hierarchy to mean that the text ignored or even the opposite of what it initially appeared to indicate. Finally, in the last step, both words of the opposition are dancing in the free play of non-hierarchical, non-stable interpretations. Based on the explanation above, the researchers assume that there are two steps in the theory of deconstruction from Derrida's perspective: identifying the opposition, deciding which one is privileged (Ibid, p. 12).

\section{STEPS OF DECONSTRUCTION}

Derrida (1981, pp. 41-42) explains in his book Position, making the researchers conclude that there are two steps to deconstruct the text. The first is to identify the opposition; the second is to decide which one is privileged.

\section{Identifying the opposition}

Deconstruction should "necessarily" operate "from the inside." According to Derrida in Ozdemir (2014, p. 62), there are two ways of finding from inside the text; pointing out the ignored parts of the texts and then challenging them, identifying their contradictions, and dealing with the binary oppositions used in the texts. In other words, if anyone wants to deconstruct a text, they should find any significant or essential parts that are underestimated or ignored and question those parts from different perspectives in order to create different interpretations.

\section{Deciding which one is privileged}

After identifying the opposition in the text, the next step is to decide which side is the privilege. As Marx in Ryan (2019, p. 22) may have claimed, privilege interpretation limits oneself to "things" at the cost of the imperceptible social contacts that create them. Furthermore, deciding the privileged term by revealing how the repressed, marginalized meaning can also be central. In order to subvert the original hierarchy from the first term over the second, this reversal step is required. Derrida (1981, p. 77) implied to change or reverse this condition to attain fairness, allowing all sides to represent themselves.

There is a specific relation between deconstruction with otherness notion. When someone is deconstructing ideas with another new idea, it is mentioned as a difference. Concerning difference, Derrida uses the term "radical otherness" (the inscription of otherrelations in the selfsame) to name difference. He takes the one that differs from himself; in other words, it is the other. Otherness is a radical element. All identity determinations are destroyed by the fundamental distinction, the relation to another. Derrida's terms for that differential relation of otherness, which breaks all "presence" of being or conscious thought apart, are "trace" (Ryan, 1999, p. 14). However, the researchers conclude that deconstruction is highly related to the notion of otherness.

\section{OTHERNESS IN TODD DURHAM'S HOTEL TRANSYLVANIA}

Some phenomena in the film assume the concept of otherness based on what Augé (2014) explained earlier, as follows:

\section{Internal use of otherness}

Internal use of otherness is simply put, as Augé (2014) explained, that the distinctness from others. The researchers conclude that this 
behavior separated the victim or oppressed from the common social set. In the film, Dracula attempts so hard to hide and vanish the man from his hotel because of Dracula's terrible memory of humans. Dracula also tried to make over the man, his appearance, to look like a monster and said if the man is normal just like us, nothing is worried about. As Staszak (2008, p. 1) said, by identifying ourselves, we identify other people. It is directly linked to 'normality' objective standards. It explains that "us" is normal, while "they" are "Other" by generalization, stereotype, and even discrimination in society and finally produce characteristics of us against them.

\section{External use of otherness}

External use of otherness, as Augé (2014) explained, is more radicalistic. It is more than just distinctness from others; moreover, it excludes and eliminates the other, for instance, from speaking. This behavior sometimes applied to the inferior or marginalized subject by the superior. For example, speaking prevention described in Hotel Transylvania, when the human came to the hotel, Dracula directly shuts his mouth and blocks his steps to make the hotel free from human contamination, as he already declared for years. It is also shown when the human interacts with his daughter, whereby Dracula feels so mad and controls their conversation.

\section{BINARY OPPOSITION}

Based on the film's manuscript through the characters, the binary opposition is between Dracs (Monster) vs. Jonathan (Human). Those characters lead the conflict between monsters vs. humankind in the film's manuscript. The following are the data that the researchers found:

Dracula (Dracs)

Datum 1.A: Judging human subjectively

Dracs: ...and another successful year of refuge from them! These are recent human images our surveillance has uncovered. They are getting fatter so as to overpower us. And they are wearing less clothing, allowing more movement to strangle us or cut open our heads and put candy in them. But they will never find us here. Evil villain, you will never win! (00:09:41).

Dracs is trying to convince all monsters that humans are dangerous and are their enemies forever. He was collecting human's photographs randomly then make a made-up story, creating a bad image of humans in front of all monsters. However, unfortunately, all monsters believe in him without any doubt.

As viewers, we might see if the human is the one who intimidates and disturbs the monster's area. On the contrary, as the leader of all monsters, Dracula is projecting humankind as all murderers. However, he creates propaganda and closes their relation to all humankind without exception.

Datum 1.B: Generalizing all humans carrying a weapon Dracs: What weapons are you keeping in this container? Your pitchforks? What is this? A torture device? A secret mind controller? You won't read my thoughts.

Jonathan: l won't let you. Dude, it's just music. (00:21:28).

Jonathan, the human, is suddenly coming to the hotel. Dracula is directly hiding him and trying to prove if Jonathan is carrying a weapon in his backpack, as what he believed ever since. However, on the contrary, Jonathan is different. He is just a traveler who lost to the hotel by chance and never wants to hurt or even kill monsters.

We have to believe if humans are afraid of monsters. Humankind is always carrying a weapon when traveling. Moreover, Jonathan is a solo traveler in a spooky forest. In contrast, he is not carrying any weapon, and even he never thinks to hurt anyone, including monsters.

Datum1.C: Underestimate and distinct humankind.

Frank: And it was so nice seeing Mavis laughing and hitting it off with him.

Dracs: Who's hitting what off? Please. Mavis could never be with someone of his kind. (00:45:25).

Dracula's words make a considerable distance between monsters and humankind. He generalizes people based on their group. Humans are wrong, so as Jonathan is.

Jonathan is a good person. Other monsters even like him. Mavis loves him because he is funny and exciting. The reason why Dracula underestimate humankind is because of his memory about human. Then, it reversed. Jonathan appeared as a new image of Dracula's inadequate representation of humankind. He could accept that when he proves by himself.

Jonathan (the human) 
Datum 2.A: Generalizing all monsters are cold-blooded killers

Jonathan: Please don't kill me. I'm so young. I have so many places l want to see.

Dracs: Shut up already. It's impossible for me to think with all your noise.

Jonathan: Wait. Aren't you going to suck my blood?

Dracs: Classic human paranoia. Human blood is so fatty, and you never know where it's been.

Jonathan: So, Dracula doesn't drink blood?

Dracs: No, l use a blood substitute. Either near Blood or Blood Beaters. You can't tell the difference.

Jonathan: So, wow, you're, like, the real Count Dracula. Like, "I'm Dracula. Bleh, bleh-bleh."

Dracs: I've never said that in my life. "Bleh, bleh-bleh." I don't know where that comes from. (00:25:44).

Humans have an image of monsters. They represent monsters as a cruel and coldblooded killer. Including Jonathan, he thought the hotel is a Halloween place or monsters festival arranged by people. After knowing he meets the real Dracula, he tried to ask for forgiveness from Dracs.

Jonathan thinks if Dracula will suck his blood. Nevertheless, after hearing Dracula's explanation, Jonathan does not believe if all about monsters are reversed.

\section{Datum 2.B: Wrong human's legend}

Jonathan: There's a whole legend around that lady.

Dracs: A legend?

Jonathan: The Lady Lubov. The story is that a lonely count met her by chance, and they say that no two souls were ever more meant for each other. Eventually, they settled down at Castle Lubov and had a child. However, then, a horrible tragedy happened. A fire started mysteriously one night, and it killed both of them. When l was at the castle, l could still feel their powerful love. They say it's as if a soul is still trapped in the ruins themselves.

Dracs : The legend is wrong. It was only the wife that died. And it was no mystery who killed her. She was killed by your kind! (00:54:35).

After knowing that Mavis has a feeling for Jonathan, Dracula thinks he has to tell why he hates humankind so much. So Dracula is trying to show Jonathan his and his wife's photograph. However, Jonathan tells a story about Dracula's wife, as she is a legend to all humans. However, unfortunately, it is a wrong legend. The story is very different.

\section{Human in general}

Datum 2.C: Wrong representation about monsters

The TV: Tell me, do you dream of being a vampire?

Dracs: This is how we're represented. Unbelievable. $(01: 16: 40)$.
When Dracula is trying to chase Jonathan in a plane, he sees a film on the cabin's TV. However, of course, he did not expect monsters' representation to be that way.

\section{DECIDING THE PRIVILEGED}

Based on the explanation in the second chapter, the next step of deconstructing is deciding which on the privileged, central, or superior, and the rest is the repressed, marginalized, or inferior, as follows:

Dracula (Dracs)

Datum 3.A: Block all Jonathan's spaces to get closer to other monsters

Frankenstein: l think my cuz is gonna make this the best party ever!

Murray: Yeah! Maybe he can find a way to get me some chicks.

Other monsters: We should do a dance contest!

Dracs: We're not doing any of that. We've got to stay on schedule, all right? (00:35:35).

Dracula's plan to get Jonathan out of the hotel is messed up. Indeed, other monsters even like him and think that he is fun. However, Dracula limits all Jonathan's moves to get closer to all monsters. He seems not happy and nervous to see Jonathan getting closer to other monsters. Dracula starts to see if Jonathan is not a threat to monsters. Nevertheless, the propaganda that had lived has to stay still around them.

Datum 3.B: Attacking the one who wants to reveal his secret

Quasimodo: A human! A human! Monsieur Dracula has brought a human into the... (Then he is freezing, and cannot speak). (00:53:32).

Quasimodo is yelling to tell all monsters if Dracs is a liar. So, Dracs, with his power, freeze him down with the aim that Quasimodo keeps silent. Quasimodo is an antagonist character who does not care that humans are not as bad as Dracula perceived; he hates humankind. However, it does not stop him from killing Jonathan.

Dracula (Dracs)

Datum 4.A: Finally, admit his thought about human is not correct

(Dracs and Jonathan are laughing)

Dracs: Who is that guy, Sir Breaks-a-lot? Oh, boy, l have to say, that was fun. $(00: 49: 54)$.

Dracula is getting mad and detains Jonathan to arrange hundreds of tables in the dining room. Still, Jonathan finds a way to make everything is fun. Then, unconsciously Dracs gets into it and starts to like Jonathan's personality. After Dracula feels how pleasurable Jonathan is, he then admits that all 
the images of humankind do not work on Jonathan. Jonathan is different from his thought.

Datum 4.B: Admit to everyone if not all humans are bad Dracs: I know 1 lied. I was wrong. But you have to believe this: Johnny wasn't a bad guy. The truth is, l don't even know if humans are bad anymore. (01:07:54).

The secret was revealed. Everyone knows if Jonathan is a human. All monsters then start to leave the hotel and ask for a refund. Finally, however, Dracula realized if Jonathan is bringing an incredible impact to monsters, especially his daughter, Mavis. Consequently, he admits and apologizes to all monsters about his lie. The stereotype that lived around monsters about humans is gone slowly-Dracula, as the one who made the propaganda, finally admits his mistakes to all monsters.

Datum 4.C: Realize if humans do not hate them

Franks: Listen, before anything else, down there's the real Dracula! Drac's daughter's in love, and he's got to get to the airport! And he can't get through this crowd! So, people, if you really are our friends, clear a path for the man!

Human in Dracula's suit: Okay. All Draculas, line up. Bleh, bleh-bleh. Everyone else, lift the capes. Protect our friend. Bleh, bleh-bleh.

People in Festival: Go get 'em! Go, Drac, go! We love you, Dracula! (01:15:10).

On the way to get Jonathan, they stuck in a people's festival in the town. They are trying to scare humans as what they believed 'only power could control them.' However, sadly, they are not scared at all. However, Franks tells everyone to help Dracula to get to Jonathan. However, then, it makes Dracula and his friends realize if the world is changing now, and they are not supposed to generalize a perception of others.

Datum 4.D: Loss of trust to Dracula

Aunt Eunice: He's not talking to you. First you tell us humans are bad, now they're good. What else? Up is down, cold is hot, gremlins don't smell. (01:08:13).

After Dracula's admission and apology, all monsters, including Franks, are confused. They do not believe if Dracula was lying. The entire humans' representation they had believed is all the opposite. They think that they are too rude to generalize if humans are all bad.
The last, the researchers find some solutions regarding these issues. The data are as follows:

\section{Mavis}

Datum 5.A: Believed that humans are not as bad as they thought

Aunt Eunice: They hate us. They're vicious. And they're very loud!

Mavis: Auntie Eunice, maybe they've changed. (00:13:50).

Even all monsters believe how bad humans are; Mavis has a different opinion about them. She thinks if it was an old story, she believes humans are not all villains and could have changed.

This kind of mindset is needed to eliminate the otherness issues. We cannot standardized people based on their ancestors.

Datum 5.B: Could accept a diversity Mavis: ls it true? Are you a human?

Jonathan: Yes. I'm so sorry.

Mavis: I don't care. I still want to be with you. (01:03:32).

Jonathan is telling the truth if he is a human. However, it makes Mavis be more like him. Unless he is honest, she does not care about that; she knows that Jonathan is a good person.

We might think monsters do not have a heart and intolerant to humankind as traditional views of monsters. However, on the contrary, as Dracula's daughter, Mavis mediates the peace between humankind with monsters.

Datum 5.C: Cannot understand each other because of "an aircraft cabin windows"

Jonathan: Wait, it's talking. Dracula? Is that you? Dracula. I can't understand you.

Dracs: What? My hand's in a tan shoe?

Jonathan: What? Japan's eating lamb stew? (01:16:57).

When Jonathan is on his way home, Dracs is chasing him to the plane. At the time, they are trying to communicate, but there is an aircraft cabin window between them. However, they could not understand a word by each other. It well-illustrates the otherness concept. We cannot understand other people because there is a gap between us.

In conclusion, otherness is closely related to deconstruction. As Mikelli (2009, p. 8 ) put it in her thesis, a close look at Kerouac's proceedings of such issues often reveals a deconstructive approach to identity and 
otherness projections. When someone deconstructs ideas with another new idea, it is referred to as a difference. He takes the one that is different from himself, the same one as the other. The relationship to the other destroys all identity determinations (Ryan, 2019, p. 14). The researchers argue, however, that deconstruction is indeed linked to the notion of otherness.

Some researchers had implemented this film as their object. Bell (2017) said that the film told about the cultural crisis nowadays, including parental fears, children's attitudes, and family issues. However, other studies focused on how cultural issues are described in the film, with the representation of Dracula as a father who is a single parent.

On the contrary, the researchers see a different perspective, which is the practical concept of otherness in the film's manuscript. Hotel Transylvania showed us how one's memory could significantly affect an interpersonal relation leading to a false identity representation and create the notion of otherness. However, to get the concept within the film's manuscript, the researchers need to deconstruct the meaning that appears in society when watching this film. As viewers, we could probably blame humans in the first place because the story leads us that way. We also had a representation of monsters before watching this film.

Derrida (1981, pp. 41-42) emphasizes two steps to deconstruct the text. The first is to identify the opposition; the second is to decide which one is privileged.

The first step in the study of deconstruction is to find the opposition. There is an opposition in the film's manuscript, in which monster vs. humankind. Both sides of them are having their perspective and representation of the other group. As the leading monster, Dracula makes an inadequate representation based on his memory about humankind and influences all monsters to think that way. Data (D.1A) showed that Dracula is trying to create and project a bad image of humankind based on his relations to the human in the past, and it manages to make the monsters think so. Hall (1997, p. 258) stated that otherness creates provocative generalizations, produces incorrect assumptions, and causing unwanted discrimination. A bad image is one of propaganda that can create conflict. (D.1B) showed that Dracula suspects Jonathan carrying a weapon to kill monsters. Hall (1997, p. 258) added that otherness allows us to view group members as being, all the same, isolate and clarify a few of the characteristics, and relate them without exceptions to a whole individual. Dracula has an inadequate representation of humankind. He thinks that humankind is cruel, killer, and sadistic.

(D.1C) explained that how Dracula assumes other parties, i.e., humankind is inappropriate to be with his kind. This datum fitted to the explanation about projecting our identity is how we project other's identity. As Okolie (2003, p. 2) indicates, otherness is highly related to identity, in which we project the identities of the others based on our experience or perception, and based on these, we unconsciously project our own identity. When Dracula thinks that humankind is inappropriate, he thinks that his group is better than humans.

On the other hand, (D.2A) and (D.2B) indicated that humans also represent monstergroup based on what they think the monster is. Humans believe in legend and myth about how horrifying monsters are. On the contrary, the fact of the monsters here is the opposite. However, not only monsters represent humankind. They represent each other based on their experience or relation to monsters, even though it has changed. Hazell (2009) said a person would make the image of otherness through the concept of the relationship he has with the "other," which will influence him in understanding and behaving towards the "other."

We could not generalize someone by his or her affiliation or origin (D.2C) is the best proof of how false representations were constituted. This scene is interesting, in which the writer acts sarcastically to people who made a false representation of others only based on their thought. Sometimes people, especially in the film industry or entertainment, are using someone else's identity, but they modified those characteristics and made a new identity on them, and sadly, it is solely for entertainment purposes.

Then, after knowing the truth about Jonathan is different from humans on his mind, he will not admit he is wrong. Instead, he 
insists on getting the human out of the hotel, as shown in (D.3A) and (D.3B). Otherness is about constructing majority and minority. This notion emerges from the intervention from the dominant. Dracula as the leader of monsters, is trying to lead the civilization beyond humankind. Therefore, he needs to keep the secret of being dominant.

(D.4A), (D.4B) and (D.4C) revealed that all facts and representations from each other group are all reverses. Dracula realizes human is not all bad from the first place he met Jonathan. At the same time, it strengthens the proof when they are in the human festival to see how friendly and helpful humans are. On the other side, Jonathan proves that no myths and legends are all true. Otherness, in representing difference, as Hall (1997, p. 258) points out, is producing incorrect assumptions. As the representation of each group, Dracula and Jonathan are creating a false representation by each other.

Data (D.4D) showed how the impact would be due to misinterpretation of other groups. Sometimes not all parties would believe the fact about the other's lousy representation. However, fear forces them to do so-fear of the leader, or fear of endangered lives, and many others. However, if the fact is revealed and the leader is proven lying, people will be confused and think clearly without any intervention.

In every issue, there has always a solution. In this film, we could find a character who will mediate to end this conflict. It is Mavis. (D.5A).

Furthermore, (D.5B) showed how we could solve this issue. Dracula and all monsters believe how bad humans are, but Mavis thinks differently. Mavis also tried to connect and clear up the conflict between monsters and humans. She believes it is all just how we present ourselves and never negatively think of the other since we cannot prove it. We need to accept diversity because we are not the only creature in this world.

Concerning the movie's conflict, the researchers find that what happened in the past has no guarantee to re-happen in the future. It is just a terrible memory from Dracula, then he brings that perception until now and generalizes humans are all the same. Likewise, humans have their perspective on monsters.
The story illustrates how parents sometimes have more chance to project others who wants to get close to their children. While the children never look at their friends just by their origin or appearance. Patcher and Garcia Coll (2009) indicated that children have fewer chances to be racist or project others as inferior. In contrast, adults and mid-ages have more prone to discriminate. Therefore, Hotel Transylvania could be a medium for criticizing those negative notions that remain in our societies nowadays.

Ciambella (2016, p. 3) stated that Hotel Transylvania's parodic universe completely subverts the Gothic cliché of a deadly but attractive vampire who fears punishment, seduces, and tries to kill his human victims. In remediation, Dracula and his friends change their results, and interpretations structure and the narrative antagonistic powers are seriously undermined. In other words, its traditional roles of villain, victim, and rescuer are subverted. At some point, if we are thinking outside of the storyline. The movie attempts to erase the scary image of monsters, including Dracula. We all know how Bram Stoker describes the image of Dracula and other myths that make us think if monsters are horrific. In addition, we could see how human (Jonathan) has an identical situation with us as the viewers.

The film shows us how misunderstanding through other people's representation could significantly impact our minds. Other people's representation all depends on what we need to think it is.

As Hooks (1997, p. 21) points out, within current debates about race and difference, mass culture is the current location that publicly declares and perpetuates the idea that there is a pleasure to be found in acknowledging racial differences. The commodification of otherness has been so successful because it offered a new delight. More intense, more satisfying than typical ways of doing and feeling.

Contemporary British working-class slang interacts jokingly with the language of sexual desire, intimacy, and the Other, evoking the term "a little of the Other" as a way to think about sexual intercourse. It is the Other to screw. Displacing the notion of otherness from race, gender, skin color, and body emerges as a position of disagreement where sexuality is a 
symbol to take over, consume, and turn through the experience of pleasure. Sexual pleasure deconstructs the notions of will, power, and manipulative domination (Ibid, 1992, p. 22).

\section{CONCLUSION}

This research has shown that the otherness concept based on deconstruction theory in Hotel Transylvania appeared in the conflict of monsters and humans. Therefore, the otherness notion will result in further discrimination and even racism. Accepting diversity and establishing good communication are ways to dispatch the concept of us vs. them, superior vs. inferior, east vs. west, radicals vs. moderates, and other similar forms that could create conflict or hostility, contrary to creating love in this beautiful life.

\section{REFERENCES}

Arnheim, Rudolf. (2006). Film As Art. London: University of California Press.

Augé, M in Cătălin-George Fedor. (2014). Stereotypes and Prejudice in the Perception of the "Other." Elsevier: Romanian Academy Iaşi Branch.

Bell, M. (2017). Learning to listen: histories of women's soundwork in the British film industry. Screen, $58(4), 437-457$.

Boggs, Joseph M, and Petrie, Dennis W. (2008). The Art of Watching Film: 7th Edition. New York: McGraw-Hill.

Derrida, Jacques. (1981). Position. Chicago: The University of Chicago Press. Translated by Alan Bass. (1981). Dissemination. The Athlone Press. Translated by Barbara Johnson.

\section{Spivak.} (1997). Of Grammatology. John Hopkins University Press. Baltimore. Translated by

Enwald, Marika. (2004). Displacements of Deconstruction (The Deconstruction of Metaphysics of Presence, Meaning, Subject, and Method). Bookshop Taju. The University of Tampere. Finland.

Ghofur. (2014). Analisis Dekonstruksi Tokoh Takeshi dan Mitsusaburo dalam Novel Silent Cry Karya Kenzaburo Oe Perspektif Jacques Derrida. A Journal Okara. Vol I.

Habib, MAR. (2005). Modern Literary Criticism and Theory (A History). Blackwell Publishing.

Hall, Stuart. (1997). Representation: Cultural Representations and Signifying Practices. London: The Open University Press.

Hazell, C. (2009). Alterity: The Experience of the Other. Bloomington: Author House.

Helsby, W. (2005). Roughs and Respectables: Representing the Other. London: BFI Publications.

Hooks, B. (1997). Representing whiteness in the black imagination (pp. 165-179). Duke University Press.

Murdocca, M. (Producer), \& Durham, T. (Writer/Director). (2012). Hotel Transylvania [Sony Picture Animation]. United States: Columbia Pictures. 
Nikmah, Hidayatun. (2014). The Representation of Heroine's Myth by "Katniss" In the Hunger Games Movie. Jogjakarta: Sunan Kalijaga State Islamic University.

Okolie, Andrew. (2003). Identity: Now You Don't See It; Now You Do. An International Journal of Theory and Research. D0I: https://doi.org/10.1207/S1532706XID0301_01

Ozdemir, Yunus. (2014). Deconstruction of Epic Beowulf in John Gardener's novel Grendel. Pamukkale University. A Journal of Social Science Institute No. XVII.

Pachter, L. M., \& Garcia Coll, C. (2009). Racism and child health: A review of the literature and future directions. Journal of Developmental and Behavioral Pedi-atrics, 30, 255-263.

Ryan, Michael. (1999). Literary Theory: A Practical Introduction. Massachusetts, USA: Blackwell Publisher.

(2019). Marxism and Deconstruction: A Critical Articulation. Maryland, USA: Johns Hopkins University Press.

Staszak, Jean-Francois. (2008). Other/Otherness. International Encyclopedia of Human Geography, https://www.unige.ch/sciencessociete/geo/files/3214/4464/7634/0therOtherness.pdf 
LiNGUA Vol. 16, No. 1, June 2021 • ISSN 1693-4725 • e-ISSN 2442-3823 